\title{
Türkiye'de ortopedi ve travmatoloji alanında patent ve faydalı model - yerli tasarımlar
}

\author{
(Ulusal patentlerin ve faydalı modellerin değerlendirilmesi) \\ Turkey in the fields of orthopedics and traumatology patent and
utility model - local designs \\ Yaşar Mahsut Dinçel ${ }^{1}$, Yunus Emre Akman², Ibrahim Azboy ${ }^{3}$ \\ ${ }^{1}$ Namık Kemal Üniversitesi Tıp Fakültesi, Ortopedi ve Travmatoloji Ana Bilim Dalı, Tekirdağ \\ ${ }^{2}$ Department of Orthopaedics and Traumatology, Mälarsjukhuset, Eskilstuna-Sweden \\ ${ }^{3}$ Isstanbul Medipol Üniversitesi Tıp Fakültesi, Ortopedi ve Travmatoloji Ana Bilim Dalı, İstanbul
}

\begin{abstract}
Bu yazının amacı Türkiye'de ortopedi ve travmatoloji alanında başvurulan, kayıt altına alınmış veya geçersiz hale gelen ulusal patent ve faydalı modellerin sayısını ve durumunu değerlendirmektir. Bildiğimiz kadarıyla, Türkiye'de ortopedi ve travmatoloji alanındaki patentlerin durumunu araştıran çalışmalar yok denecek kadar azdır. Bizim ulaştığımız tek çalışmadan elde ettiğimiz bilgilere göre, omurga cerrahisi ve travma ile ilgili patentler ilk sıradadır. Yine bu makaleden edindiğimiz bilgiye göre ödenmemiş yıllık patent ücretleri nedeniyle patent başvurularının üçte biri geçersiz olmuştur. Ortopedi ve travmatoloji ya da diğer alanlardaki patent ve faydalı modelleri araştıran gelecekteki çalışmaların artması ile ilerde bu bilgilerimiz daha artacak ve Türkiye'deki bu durum daha net anlaşılacaktır.

Anahtar sözcülkler: ortopedi; patent; travmatoloji; faydalı model; Türkiye
\end{abstract}

\begin{abstract}
The aim of this article is to evaluate the number and the status of the national patents and the utility models which have been applied for, recorded or invalidated, in the field of orthopedics and traumatology, in Turkey, is. To the best of our knowledge, the number of the studies investigating the status of the patents the field of orthopedics and traumatology in Turkey is so low as to be negligible. According to the information we obtained from the unique study we have reached, the patents related with spine surgery and trauma surgery are in the first place. Furthermore, according to the information we obtained from this article, one third of the patent applications were invalid due to the unpaid annual patent fees. As the number of the future studies investigating the patents and utility models in the field of orthopedics and traumatology or in other areas, our present knowledge will increase as well and the situation in Turkey will be better understood.
\end{abstract}

Key words: orthopedics; patent; traumatology; useful model; Turkey

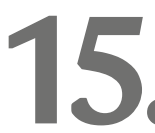

yüzyılda Venedik Patent Yasası ile buluşların patent ile korunması uygulanmaya başlanmıştır. ${ }^{[1,2]}$ Kamunun faydası için buluşçuluğu teşvik etmek ve buluşçuluk onurunu korumak amaçlanmıştır. ${ }^{[1,2]}$ Dünyada bu konu ile ilgili ikinci yasa 1624 yılında İngiltere'de yürürlüğe giren patent yasasıdır. Diğer patent yasaları ise sırası ile; 1790 Amerika Birleşik Devletleri, 1791 Fransız, 1877 Alman ve 1879 Türk Patent Yasaları'dır.

Patent yasalarının tarihsel sürecine baktığımızda, Türk Patent Yasası'nın Dünya Patent Yasaları'nın ilklerinden olduğu görülmektedir. ${ }^{[1,3]}$ Türk Patent Enstitüsü
(TPE), Türkiye'nin teknolojik ilerlemesine katkıda bulunmak, ülke içinde serbest rekabet ortamını oluşturmak ve araştırma-geliştirme faaliyetlerinin geliş̧mesini sağlamak üzere, patent ve markalar ile yurt içi ve yurt dışında bilgi ve materyalin kamunun yararına sunulabilmesi amacıyla kurulmuştur. ${ }^{[3]}$ Patent, sınırlı bir yer ve süre için üçüncü kişiler tarafından buluşun izinsiz olarak üretilmesini, kullanılmasını veya satılmasını engeller. Bu hakkın kullanabileceğini gösteren belgeye ise patent belgesi (PB) denir. ${ }^{[1,4]}$

Faydalı model (FM) ise dünya çapında yeni olan ve sanayiye uygulanabilen buluşların korumasını sağlayan

- İletişim adresi: Dr. Ögr. Gör. Yaşar Mahsut Dinçel, Namık Kemal Üniversitesi Tıp Fakültesi, Ortopedi ve Travmatoloji Ana Bilim Dalı, Tekirdağ Tel: 0533 - 4287326 e-posta:Ymd61@hotmail.com ORCID iD: 0000-0001-6576-1802

- Geliș tarihi: 12 Kasım $2020 \quad$ Kabul tarihi: 26 Kasım 2020

Yunus Emre Akman, ORCID iD: 0000-0003-2939-0519 ibrahim Azboy, ORCID iD: 0000-0003-0926-3029 
bir mülkiyet hakkıdır. ${ }^{[4]}$ Faydalı model belgesi (FMB), PB'ye göre daha kısa zamanda ve daha az bir masrafla alınabilmektedir. FM ile fikri koruma sağlama sürecinin PB'ye göre göreceli olarak daha basit ve ucuz olmasının, araştırma kuruluşlarımızın buluş yapmalarını özendireceği düşünülmüşsürr.

FM için buluş basamağı kriteri aranmamaktadır. ${ }^{[4]}$ Buluş basamağı içermediği için FM belgesi alacak ürün ve yöntemlere FM koruması sağlanmamaktadır. FMB alma süreci PB'ye göre daha az maliyetle ve daha kısa sürede gerçekleşmesi başvuru sahibinin lehinedir. ${ }^{[1,4]}$

Nice Anlaşması (1957) tarafından oluşturulan Nice sınıflandırması, markaların tescili için uygulanan mal ve hizmetlerin uluslararası bir sınıflandırmasıdır. ${ }^{[1,4]}$ Türk Patent ve Marka Kurumu veritabanı da bu sınıflandırmayı kullanmaktadır. TPE'ne marka alanında başvuru yapmış firmalar Avrupa Topluluğunda Ekonomik Faaliyetlerin İstatistiki Sınıflaması olan Nomenclature of Economic Activities (NACE) kodlarına göre sınıflandırılır. ${ }^{[1,4]} \mathrm{N}$ ve $\mathrm{Q}$ harfi sağlık alanını simgelemektedir. Ortopedi ve travmatoloji alanına en yakın patent ve faydalı modelleri A61B17, A61F2 ve A61F5 sınıflandırma kapsamında yer almaktadır.

A61B17 patenti cerrahi aletler, cihazlar veya yöntemleri içermektedir. A61F2 patenti kan damarlarına implante edilebilir filtreler; protezler, diğer bir deyişle, vücudun bazı kısımları için yapay ikame ya da değiştirmeler; gövdeye bağlamak için kullanılan aletler; vücudun tubular şeklindeki yapılarının açıklığa kavuşmasını sağlayan ya da çökmeyi önleyen cihazları içermektedir. A61F5 kemik veya eklemlerin cerrahi dışı tedavisinde kullanılan ortopedik yöntemler veya cihazları içermektedir.

Dinçel ve ark.'nın çalışması 2007-2017 yılları arasını incelemiştir. TPE kurumu üzerinden bir araştırma yapılmış ve ortopedi ve travmatoloji alanında toplamda 336 adet patent ve faydalı model çalışmaya dahil edilmiştir. Bu çalışmada patent ve faydalı modeller konularına göre kategori ve alt kategorilere ayrılmış. ${ }^{[1]}$

Bu çalışmaya göre; A61F2 patent sınıfında toplam 109 patent ve faydalı model bulunmuştur. Bunlardan 29 tanesi başvuru aşamasında, 57 tanesi tescil almış, 23 tanesi ise mevzuattaki ücret yatırma sorunu nedeni ile geçersiz sayılmış olduğu bildirilmektedir. Bu patent sınıfına kategorik olarak bakıldığında en fazla patent ve faydalı modelin omurga cerrahisi alanında alındığı $(\% 44,9)$ görüldü. Diğer patent ve faydalı modellerin sırasıyla ortez alanında $(\% 21,5)$, artroplasti alanında $(\% 11,2)$ ve spor cerrahisi alanında $(\% 3,7)$ alındığı görüldü. En az ise \%1,9 oran ile tümör cerrahisi alanında patent ve faydalı modelin yer aldığı görüldü. Pediatrik ortopedi ve mikrocerrahi alanında ürün bulunmamaktadır. ${ }^{[1]}$

Alt kategori olarak bakıldığında en fazla sayıda patent ve faydalı modelin implantlar alanında alındığı, en az ise fiksatörler alanında alındığı görülmektedir. El aleti açısından patent ve faydalı model bu grupta bulunmamaktadır. Alt gruplarda yüzde olarak değerlendirildiğinde $\% 60,7$ implantlar ilk sırada, protezler $\% 21,5$ ile ikinci sırada, en az oranda ise \%1,9 ile fiksatörler yer almaktadır. ${ }^{[1]}$

Yine bu çalışmada A61B17 patent sınıfında toplam 204 adet patent ve faydalı model bulunmaktaydı. Bunlardan 36 tanesi başvuru aşamasında, 103 tanesi tescil almış, 65 tanesi ise mevzuattaki ücret yatırma sorunu nedeni ile geçersiz sayılmıştı. Bu patent sınıfına kategorik olarak bakıldığında en fazla sayıda patent ve faydalı modelin travma alanında alındığı $(\% 42,1)$, en az sayıda patent ve faydalı modelin ise mikrocerrahi alanında alındığı $(\% 0,5)$ görüldü. Ortez, tümör cerrahisi ve pediatrik ortopedi alanında patent ve faydalı model bulunmamaktadır. Alt kategori olarak bakıldığında en fazla patent ve faydalı modelin implantlar alanında alındığı $(\% 64,9)$, en az patent ve faydalı model biyomalzeme (\%1) üzerine alındığı görülmektedir. ${ }^{[1]}$

Bahse konu olan bu çalışmada A61F5 patent sınıfinda toplam 28 adet patent ve faydalı model bulunmaktaydı. Bunlardan 8 tanesi başvuru aşamasında, 12 tanesi tescil almış, 8 tanesi ise mevzuattaki ücret yatırma sorunu nedeni ile geçersiz sayılmıştı. Bu patent sınıfına kategorik olarak bakıldığında en fazla patent ve faydalı modelin ortezler alanında alındığı $(\% 48,1)$, en az sayıda patent ve faydalı modelin ise pediatrik ortopedi alanında alındığı $(\% 3,7)$ görüldü. Genel ortopedi, tümör cerrahisi, spor cerrahisi, artroplasti ve mikrocerrahi alanında çalışma bulunmamaktadır. Alt kategori olarak bakıldığında en fazla patent ve faydalı modelin protezler alanında alındığı $(\% 48,1)$, en az sayıda patent ve faydalı modelin ise yardımcı aletler $(\% 11,1)$ ve fiksatörler $(\% 11,1)$ alanında alındığı görülmektedir. ${ }^{[1]}$

Yıllara göre ürünlerin analizi yapıldığında en çok 2012 yılında $(\% 23,2)$ patent ve faydalı model üretildiği görülmektedir. Bunu sırasıyla $2014(\% 16,1)$ ve $2015(\% 11,6)$ yılları takip etmektedir. En az patent ve faydalı model üretilen yıl ise 2008 'dir $(\% 5,4) \cdot{ }^{[1]}$

Günümüzde patent bilgi toplumunun ana unsurlarındandır. ${ }^{[5]}$ Patent, buluş sahibine belirli bir süre için verilir. Buluş konusu ürünün izinsiz olarak başkaları tarafından üretilmesini, kullanılmasını veya ticaretinin yapılmasını engeller. ${ }^{[1,6]} \mathrm{Bu}$ hak buluş sahibine aynı zamanda, hakkını üçüncü kişilere devretmek, 
belirli bir süre için üçüncü kişilerin buluştan yararlanmasına izin vermeyi de kapsar. ${ }^{[7]}$

Bilebildigimiz kadarı ile Türkiye'de hem ortopedi ve travmatoloji alanında ve hem de sağlık sektöründe patent ve faydalı modeller ile ilgili daha önce yapılmış bir çalışma bulunmaktadır. ${ }^{[1,6,8]}$

Türkiye olarak sağlık ürünleri alanında dışa bağımlılığı en az seviyeye getirmek, yeni ve yararlı ürünleri geliştirmek amacıyla patent ve faydalı model başvurularına ve daha sonraki süreçlere desteğin arttırılması yararlı olacaktır. ${ }^{[1,9]}$

\section{KAYNAKLAR}

1. Dinçel $Y M$, Akman $Y E$, Gür AU, Demir T, Azboy i. An evaluation of national patents and utility models during the last decade in the field of orthopedics and traumatology in Turkey. Cumhuriyet Med J 2019;41:3. Crossref
2. Karaahmet E. Bilgi Kaynağı Olarak Patentler, Markalar ve Türk Patent Enstitüsü. Türk Kütüphaneciliği 1995:9;386-97. https://core.ac.uk/download/pdf/236285177.pdf

3. Ortan AN. Avrupa Patent Sistemi: Cilt 1. Avrupa Patenti Antlaşması (Münih Antlaşması). Ankara: Banka ve Ticaret Hukuku Araştırma Enstitüsü; 1991.

4. Türk Patent ve Marka Kurumu, (Bilim, Sanayi ve Teknoloji Bakanlığı'nın) Patent/Faydalı Model başvuru kılavuzu 2014.

5. Petersmann EU. Human Rights and the Law of the World Trade Organization. J World Trade 2003;37:241-81.

6. Langinier C, Moschini GC. The Economics of Patents: lowa State University, Center for Agricultural and Rural Development, Working Paper, No. 02-WP 293.

7. Scherer FM. Industrial Market Structure and Economic Performances, 2nd ed. Chicago: Rand-McNally; 1980.

8. Türk Patent Enstitüsü'ne Marka, Endüstriyel Tasarım ve Patent Alanlarında Başvuru Yapmış Firmaların Sektörel Dağılımı, 2008.

9. Uğur G, Yalçıner UG. Türkiye'de patent sistemi ve yönetiminin bugünü ve yarını. Patent Sistemleri ve Patent Ofis Organizasyonları Uluslararası Sempozyumu, 12-13 Ekim 1992. 